\title{
Developing a Quality Checklist for Designing Blended Learning Course Content
}

\author{
Sahreen Chauhan, Azra Naseem, and Eman Rashwan
}

\begin{abstract}
This paper describes the process of developing a quality assurance checklist for course designers and faculty members who are engaged in designing blended learning courses at a multi-campus private university. The purpose is to establish unified quality criteria for ensuring quality of the design of blended learning course content. Six categories were identified in the checklist to meet the purpose: 1) contact information, copyrights, 2) privacy and security of information, 3) nature of interactive online content, 4) usability, 5) multimedia, and 6) interface design and technical specifications. Four stages of the checklist development were followed during the process: initial discussion for item adaption, validity and reliability assessment, tool/checklist refinement and finalization. These stages were found to be useful in creating the quality checklist for designing the course content taught through blended learning approaches.
\end{abstract}

Index Terms-Blended learning, course design, checklist development, quality assurance.

\section{INTRODUCTION}

The Aga Khan University (AKU) is an international University spread across 8 geographical sites in three continents (Africa, Asia and Europe). To enable increased collaborative teaching across campuses, AKU initiated a blended learning programme. In a blended learning approach, a combination of synchronous and asynchronous technologies is used to offer courses.

In order to enable faculty members to design and teach courses through a BL approach, a professional development programme is offered. The programme itself is designed in the blended learning format in order to give practical experience of this approach to the faculty members. The programme consists of a four-week online learning phase and a face-to-face workshop of two weeks, where faculty members participate in various activities to gain knowledge and skills of designing and teaching through blended learning approaches. After the face-to-face workshop, the faculty-participants are facilitated and mentored by a team of eLearning designers and developers, to redesign an existing face-to-face course and offer it in a blended format.

There are a number of faculty members and course designers working on course design and development within the university. In order to ensure consistency of design features across the courses, a need was identified to establish unified quality criteria that can be followed by all

Manuscript received August 30, 2014; revised October 22, 2014.

The authors are with Aga Khan University, Pakistan (e-mail: sahreen.chauhan@aku.edu, eman.rashwan@aku.edu). stakeholders. In this paper the process of developing the quality assurance checklist will be described.

\section{Defining Quality e-LeARning / BLENDED LEARNING COURSES}

In order to ensure successful implementation and continuous improvement of teaching through BL approaches it is important for the institutions to undertake various research and quality assurance initiatives. Thus, to understand what is meant by 'quality' and how it is defined for the courses offered at the institution becomes the most significant step [1]. Defining a quality assurance process is challenging also because it requires the institution to focus not only on learning outcomes, but also on the process of improving course design and teaching using ICT [2].

Many Higher Education institutions have developed quality review processes for blended learning courses and implement them on a routine basis[3], [4]. For example, Centre for Teaching and Educational Technologies (CTET) at Royal Road University conducted a pilot project to create a review process for online courses, which are now part of their regular practice to ensure ongoing improvement. Six independent but interrelated components were identified for the online quality courses by CTET: 1) curriculum design, 2) teaching and facilitation, 3) learning facilitation, 4) instructional design, 5) web design and 6) course presentation [3].

Ratnasingam (2014) in her study examined quality indicators related to the online course design and delivery and its impact on students' learning [4]. These components are course structure, course content, course navigation and course assessments.

Quality and standards are used differently in different educational contexts. Quality in teaching and course design in eLearning may refer to course content with clear objectives; teaching activities, strategies and resources linked to the course objectives; contact information and the ways to correspond with the teacher; information on the copyright and information security [5].

In 1987, Gamson and Chickering proposed seven research-based principles of good teaching practice in Colleges and Universities. These are: 1) encourages contact between students and faculty, 2) develops reciprocity and cooperation among students, 3) encourages active learning, 4) gives prompt feedback, 5) emphasizes time on task, 6) communicates high expectations, 7) respects diverse talents and ways of learning. These principles are applicable to online and blended learning environments as well [6]. Dayton and Vaughn (2007) established a quality assurance process 
using these seven principles as a framework and developed a checklist to review their online courses [7]. The checklist was meant to be used by the faculty members as good practice guidelines in designing new or revising their existing online courses and also by the instructional designers to carry out the QA review of the courses. The authors found that the QA framework needs to be comprehensive, concise and adaptable to all type of course (including course which are not taught online) to promote good practices. Moreover, a framework (based on seven principles), as in this case, was found to be useful for developing course and faculty evaluations questionnaires.

Whilst most of the checklists were about evaluating the quality of the entire process of course design, a need was felt to develop a checklist that could guide the process of designing course content.

\section{PROCESS}

A checklist was developed to ascertain the quality of the course content designed by the course designers and the faculty members. The process of developing the tool comprised four steps:

1) Initial decisions for item adaptation

2) Validity assessment

3) Reliability assessment

4) Tool refinement and finalization

\section{A. Initial Decisions for Item Adaptation}

The process began with a discussion amongst course designers and faculty members on what constitutes quality of course content in a blended format. Subsequently, a list of items was developed by the two course designers, and three tools were considered more closely.

The first one was shared by designer A (third author of this paper) that she had used in her previous content development work for evaluating the eLearning content and online courses of different higher education institutions and corporates in the Middle East. The checklist had 35 items divided into seven sections to measure the minimum quality standards of content, instructional design, course outline, learning environment, intellectual property usability and technical aspects.

The second one was based on the Seven Principles for Good Practice in Undergraduate Education by Chickering and Gamson (1987). This checklist was developed by the University team to review blended learning courses, and had 65 items divided in seven sections on a scale of 1 to 5 .

The third checklist was developed by Vai and Sosulski (2011) [8]. This included 87 items related to ten essential elements of online course design such as learning outcomes and content, ease of communication, pedagogical and organizational design, visual design, engaged learning, collaboration and community, assessment, feedback evaluation and grading, and ease of access.

As a result of considering the tools, a new checklist (version A) was developed taking into consideration the University needs and the scope of work. Table I gives an overview of the version A of the checklist. It comprised 45 items arranged in 6 categories: 1) Contact information, 2) Copyrights, Privacy and Security of Information, 3) Nature of interactive online content,4) Usability, 5) Multimedia and interface design and 6) Technical specifications. Each item was measured on a 5-point scale: $1=$ not at all, $2=$ minimally, $3=$ fairly, 4=mostly, 5=completely.

\begin{tabular}{lc}
\multicolumn{1}{c}{ TABLE I: OVERVIEW OF THE CHECKLIST (VERSION A) } \\
\hline \hline \multicolumn{1}{c}{ Categories } & Number of items \\
\hline Contact information & 8 \\
Copyrights, Privacy and Security & 4 \\
of Information & \\
Nature of interactive online & 13 \\
content & \\
Usability & 9 \\
Multimedia and interface design & 8 \\
Technical specifications & 3 \\
\hline \hline
\end{tabular}

The first category included items related to faculty members' contact information, hours when they were available to the students, the minimum expected response time to students' queries and information about availability of IT Help desk support for the students. The availability of information regarding how to contact faculty and support staff members was meant to help in creating a supportive environment for students who might be studying in this mode for the first time. For example, by mentioning the time it would take a faculty member to respond to their email queries would help in managing students' expectations of faculty's availability during the online teaching.

The second category contained items about the use of copyright materials on the course website. The items related to students' privacy rights and their data protection on the course website were included. The University follows a process of seeking copyright clearance of external materials that are placed on the course website. Also, there are policies regarding students' data protection. Hence, these were included in the checklist. For example, "Course materials contain statements clarifying ownership and usage rights where appropriate".

The third category contained items that measure whether or not online activities promote student-student and student-teacher interaction. These types of interaction are essential to ensure student engagement in the learning process. For example, an item was included: "online activities promote student-student interaction and collaboration (e.g. use of discussion forum, wikis, Google docs etc. for group projects, cooperative learning)."

The fourth and fifth categories measured the ease of use, multimedia and design quality of the course website, respectively. They included items related to the design, navigation and course architecture. For example, these items were included: "Instructions are clear to complete activities and assignments, links to various sections on the website are linked" and "The online interface design has a clear and logical layout of content."

The sixth category comprised items related to the hardware and software requirements for course activities, portability of the content and also the 'Sharable Content Object Reference Model (SCORM)' aspects (SCORM 1.2 complaint). For example, "the digital media content has been designed to be accessed on multiple types of devices (portability)".

\section{B. Validity Assessment}


Face validity was performed to ensure the items and measures assessed the categories identified in the tool. A blended learning expert performed the face validity. The reviewer looked at the checklist, read all the items and agreed that the items in the checklist appeared to be measuring the main aspects of the blended learning content design (e.g. contact information was available, the design of course website interface is user-friendly, and materials used are copyrighted).

For content validity, the checklist was sent to three reviewers, who had experience in designing courses for blended learning. The reviewers were asked to rate their opinion on a five-point scale on the "relevancy" (' 1 ' being completely irrelevant to ' 5 ' being completely relevant) of each item according to their understanding of the essential components for a blended learning course website. Moreover, they were asked to comment on various aspects of the tool (e.g. clarity of language, appropriateness) and give suggestions to further improve the items in the tool.

All the items were rated between 'relevant' and 'completely relevant' by the three reviewers. The following changes were made based on the comments from the reviewers:

1) A few items were re-phrased and examples were added.

For instance, the item "Students are required to post their contact information online so they may communicate with each other early on the course" was re-written as "Students are required to post their contact information early on the course, so they may communicate with each other."

2) Three items were deleted from the nature of interactive online content category. These included items like "the importance of scheduling/using time wisely is emphasized during the orientation week/module"; "students' initial knowledge about the use of relevant ICTs is assessed within the first week of starting the course and/or module". These items were related to students' orientation programme and hence were found irrelevant to the course design.

The revised checklist after the content review (version B) contained 42 items (Table II).

TABLE II: OVERVIEW OF THE CHECKLIST AFTER CONTENT REVIEW (VERSION B)

\begin{tabular}{lc}
\hline \hline \multicolumn{1}{c}{ Categories } & Number of items \\
\hline Contact information & 8 \\
Copyrights, Privacy and Security of & 4 \\
Information & \\
Nature of interactive online content & 10 \\
Usability & 9 \\
Multimedia and interface design & 8 \\
Technical specifications & 3 \\
\hline \hline
\end{tabular}

\section{Reliability Assessment}

The tool, after the content review, was sent to two raters to establish the inter-rater reliability. Both the raters had knowledge and experience of eLearning design and blended learning course content development.

The raters were given access to a course site, which was previously taught through blended learning approaches. They reviewed the course website using the checklist. The data from both the reviewers were entered into Statistical Package for the Social Sciences (SPSS 20.0) to measure the level of agreement (kappa, $\rho$ ) between the two raters.

The results in Table III show a moderate level of agreement between the two raters and the difference is found to be statistically significant $(\rho=0.41, p<0.001)$ [9].

Due to the difference in the rating of the two raters, team met the raters and had a follow-up discussion on their rating of the items for refinement and finalization.

\section{Tool Refinement and Finalization}

Based on the results obtained from the reliability analysis and qualitative remarks obtained by the raters, a discussion was carried out with them individually. The purpose was to ascertain their understanding and rationale for their ratings of the items in the checklist, especially where there were marked differences between the two raters.

TABLE III: INTERRATER RELIABILITY RESULTS

\begin{tabular}{lllll}
\multicolumn{4}{c}{ TABLE III: INTERRATER RELIABILITY RESULTS } \\
\hline \hline & Value & $\begin{array}{l}\text { Asymp. } \\
\text { Std. Error }\end{array}$ & $\begin{array}{l}\text { Approx } \\
\mathrm{T}^{\mathrm{b}}\end{array}$ & $\begin{array}{l}\text { Approx. } \\
\text { Sig }\end{array}$ \\
\hline $\begin{array}{l}\text { Measure of } \\
\begin{array}{l}\text { Agreement } \\
\text { (Kappa) }\end{array}\end{array}$ & .410 & 0.089 & 5.004 & .000 \\
\begin{tabular}{l} 
No. of valid cases \\
\hline \hline
\end{tabular} & 40 & & & \\
\hline
\end{tabular}

a. Not assuming the null hypothesis.

b. Using the asymptotic standard error assuming the null hypothesis.

The discussion helped decide whether to keep an item as it was written, modify/rephrase it or delete it completely.

The key findings from the discussion are as follows:

1) A few items needed to be rephrased to make them more relevant. For example, "The faculty's role in reminding/ encouraging students when they do not complete the tasks on time is clearly articulated" was rephrased as "A schedule of timelines is provided to clearly guide students by when events and learning activities should be accomplished."

2) Examples were added for clarification. For example, in one item, APA was added as an example: "all quoted materials are cited correctly by adhering to one of the standard citation format (e.g. APA)."

3) Duplicate items were deleted. For example, "Data protection policies are clearly stated where required" and "Steps have been taken to protect students' educational records/privacy rights (e.g. it is a password protected site)", were merged as "Course websites are password protected and only authorized users are provided access to the site."

4) The rating scale from a five-point scale was changed to three categories, namely, 'Yes', 'No' and 'Not applicable' in order to be more precise.

TABLE IV: OVERVIEW OF THE FINAL VERSION OF THE CHECKLIST (VERSION

\begin{tabular}{lc}
\multicolumn{1}{c}{ C) } \\
\hline \hline \multicolumn{1}{c}{ Categories } & Number of items \\
\hline Contact information & 7 \\
Copyrights, Privacy and Security of & 3 \\
Information & \\
Nature of interactive online content & 11 \\
Usability & 6 \\
Multimedia and interface design & 6 \\
Technical specifications & 2 \\
\hline
\end{tabular}


During the discussion, it was observed that training faculty members, the course designers and other stakeholders to use the checklist is needed in order to ensure uniform understanding of each item.

The authors finalized the checklist after carefully reviewing each discussion point (Version C). Table IV gives an overview of the final version of the checklist. It comprised a total of 35 items.

\section{CONCLUSION}

This paper has described the process of developing a checklist for quality assurance of the course content that is used as a part of courses offered through blended learning approaches. The process and findings highlight the importance of developing and using tools that are contextually relevant. The reliability and validity testing showed the importance of stating the items clearly; adding examples with items, having less number of items to keep the overall length of the tool short, and reduce redundancy. Along with a checklist for the review of the course website, it would be necessary to establish quality standards for a blended course that are overcharging and include other aspects of the teaching and learning process. The checklist will be implemented in the final quarter of 2014. Future studies will capture the experiences of various faculty members, eLearning designers and developers of using the checklist, and to design quality standards for the entire blended teaching and learning process.

\section{REFERENCES}

[1] V. Diaz and M. Brown. (November 2010). Blended learning: A report on the ELI focus session. Educause Learning Initiative paper 2 [Online]. Available: http://net.educause.edu/ir/library/pdf/ELI3023.pdf

[2] R.A. Ellis and R. A. Calvo, "Minimum indicators to assure quality of LMS-supported blended learning," Educational Technology \& Society, vol. 10, no. 2, pp. 60-70, 2007.

[3] T. Chao, T. Saj, and F. Tessier. (January 2006). Establishing a quality review for online courses. The Educause Review. [Online]. Available: http://www.educause.edu/ero/article/establishing-quality-review-onlin e-courses

[4] P. Ratnasingam, "Quality indicators that impact the design and delivery of online instruction," Journal of Contemporary Issues in Business Research Volume, vol. 3, no. 1, pp. 19-34, 2014.

[5] C. Ceobanu and L. Asansului, "A theoretical framework for quality indicators in elearning," Turkish Online Journal of Distance Education, vol. 10, pp. 126-135, October 2009.
[6] A. W. Chickering and Z. F. Gamson. (1987). Seven principles for good practice in undergraduate education. Washington Center News. [Online]. http://www.lonestar.edu/multimedia/SevenPrinciples.pdf Available:

[7] D. Dayton and M. M. Vaughn. (November 2007). Developing a quality assurance process to guide the design and assessment of online courses. Technical Communication. [Online]. Available: http://www.academia.edu/3779012/Developing_a_Quality_Assuranc e_Process_to_Guide_the_Design_and_Assessment_of_Online_Cours es

[8] M. Vai and K. Sosulski, Essentials of Online Course Design: A Standards-Based Guide, New York: Taylor \& Francis, 2011

[9] J. R. Landis and G. G. Koch, "The measurement of observer agreement for categorical data," Biometric, vol. 33, pp. 159-174, March 1977.

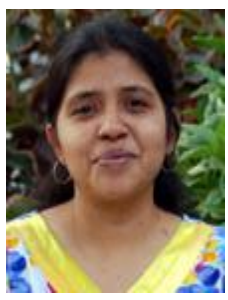

Sahreen Chauhan has done her master degree in applied mathematics from the University of Karachi, Pakistan.

She is the senior research coordinator, blended and digital learning network at the Aga Khan University. She manages collaborative research studies conducted during the faculty development programme in blended and digital learning. Her research interests include the use of digital media technologies in education, and cognitive tests and tools development.

Ms. Chauhan has worked as a teacher educator and a researcher for 8 years in the same institution.

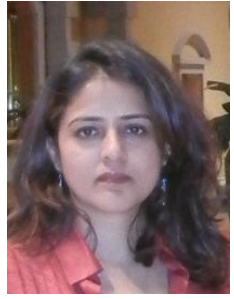

Azra Naseem has a master degree in elearning from University of Technology Sydney Australia, and in linguistics from University of Karachi Pakistan. Her research and teaching is in the area of elearning and ICT enhanced teaching in higher education.

She is currently the assistant director blended and digital learning network, and a faculty member at the Aga Khan University. Her publications include: "Collaborative tools for research, development, and professional service," Ethnicity and Race: Creating Educational Opportunities Around the Globe, etc.

Ms. Naseem has received the Best Teacher Award at the Aga Khan University. She is also the recipient of Commonwealth Youth Leadership Award in 2005 .

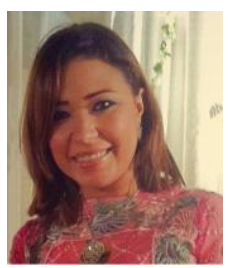

Eman Rashwan is a senior instructional designer and e-learning consultant at Aga Khan University

She has done her bachelors of computers and information from Cairo University Egypt and diploma in e-learning from the Information Technology Institute, Egypt. She holds requirements engineering certified from the American University, Egypt.

Prior to her current role as a blended and digital learning specialist, she has worked for 7 years in e-course design and development for Middle East Universities and Educational institutions. 